\title{
UMA REFLEXÃO SOBRE O DESENVOLVIMENTO DE PRÁTICAS DE ENSINO ACERCA DAS QUESTÕES AMBIENTAIS
}

\section{DianA PAULA Diogo CORREIA}

Programa de Pós-graduação em Ensino, Educação Básica e Formação de Professores - Universidade Federal do Espírito Santo

E-mail: dianapauladiogo@gmail.com

\section{LUCELI DE SOUZA}

Programa de Pós-graduação em Ensino, Educação Básica e Formação de Professores - Universidade Federal do Espírito Santo

E-mail: lucelidesouza@yahoo.com.br

\section{RESUMO:}

A inserção da temática ambiental sob prática educativa interdisciplinar visa a formar sujeitos éticos em relação ao meio ambiente em todos os fenômenos: físicos, químicos, biológicos e sociais. Na realidade, nota-se uma abordagem reduzida a temas fragmentados distantes do contexto social dos alunos. Este ensaio teórico apresenta, a partir de uma revisão de literatura, os aspectos trazidos por autores para a reflexão pelo professor da Educação básica no planejamento e desenvolvimento de práticas de ensino acerca das questões ambientais considerando a diversidade socioeconômica e cultural dos alunos e da comunidade em que estão inseridos, sem ignorar as dificuldades no exercício da carreira docente e a responsabilidade da escola com um trabalho pedagógico personalizado.

\section{PALAVRAS-CHAVE:}

Educação ambiental; diversidade; prática pedagógica; educação básica.

\section{A Reflection on the DeVElopment of Teaching PRactices about the EnVIRonmental Issues}

\section{ABSTRACT:}

The insertion of the environmental theme in the interdisciplinary educational practice aims to form ethical subjects about the environment in all phenomena: physical, chemical, biological, and social. In reality, there is a reduced approach to fragmented themes that are far removed from the students' social context. This theoretical essay presents, from a literature review, the aspects brought by authors for reflection by the teacher of Basic Education in the planning and development of teaching practices about environmental issues considering the socioeconomic and cultural diversity of the students and the community in Which are inserted, without ignoring the difficulties in the exercise of the teaching career and the responsibility of the school with a personalized pedagogical work.

\section{KEYWORDS:}

Environmental education; diversity; pedagogical practice; basic education. 


\section{INTRODUÇÃO}

Quando se fala em Educação ambiental, pensa-se imediatamente nas imagens de rios contaminados, lixo, poluição do ar, aquecimento global e desmatamento da Amazônia. Ainda que tenha nascido da emergência ecológica planetária, considerar somente as dimensões ecológica e conceitual da Educação ambiental significa reduzir e simplificar a complexa trama de relações entre a educação e o ambiente. Sendo assim, a discussão não só deve abranger o meio ambiente físico como também abordar a realidade local e toda a complexidade das relações entre meio ambiente e sociedade (LUZZI, 2012; PEREIRA; MELO; FERNANDES, 2012).

A Resolução no 2, de 15 de junho de 2012, que estabeleceu as Diretrizes Curriculares Nacionais para a Educação Ambiental (DCNEA) traz, em seu artigo 6으, esse direcionamento:

[...] A Educação ambiental deve adotar uma abordagem que considere a interface entre a natureza, a sociocultura, a produção, o trabalho, o consumo, superando a visão despolitizada, acrítica, ingênua e naturalista ainda muito presente na prática pedagógica das instituições de ensino [...] (BRASIL, 2012, p. 2).

Conforme esclarecem as DCNEA, o atributo ambiental da Educação ambiental não é empregado para adjetivá-la, e sim para identificar uma dimensão da educação que deve ser trabalhada no currículo escolar com a intenção de inspirar no indivíduo uma ética ambiental em sua relação com a natureza e os outros seres humanos, bem como promover a formação de atitudes e valores sociais (BRASIL, 2012).

A inserção da temática ambiental no currículo escolar não deve ser, obrigatoriamente, sob forma de disciplina ou componente curricular específico. Para o trabalho nessa dimensão, as DCNEA indicam uma prática educativa integrada e interdisciplinar que perpassa todas as fases, etapas e modalidades de ensino, respeitada a autonomia da escola para selecionar os conteúdos a serem desenvolvidos considerando a diversidade sociocultural de seus alunos e da comunidade na qual se 
encontra inserida, conforme disposto no inciso $\mathrm{VI}$ do artigo 12 e artigo 16 do referido documento:

[...] VI - respeito à pluralidade e à diversidade, seja individual, seja coletiva, étnica, racial, social e cultural, disseminando os direitos de existência e permanência e o valor da multiculturalidade e plurietnicidade do país e do desenvolvimento da cidadania planetária. [...] (BRASIL, 2012, p. 4).

Art. 16. A inserção dos conhecimentos concernentes à Educação ambiental nos currículos da Educação Básica e da Educação Superior pode ocorrer:

I - pela transversalidade, mediante temas relacionados com o meio ambiente e a sustentabilidade socioambiental;

Il - como conteúdo dos componentes já constantes do currículo;

III - pela combinação de transversalidade e de tratamento nos componentes curriculares. [...] (BRASIL, 2012, p. 5).

As DCNEA, conforme artigo 17, apontam como dever da gestão da instituição de ensino contribuir para a promoção do cuidado com as diversas formas de vida e do respeito às pessoas, culturas e comunidades por meio de um tratamento pedagógico diversificado que permita o reconhecimento e a valorização da pluralidade e das diferenças individuais, sociais, étnicas e culturais dos alunos e promova valores de cooperação, de relações solidárias e de respeito ao meio ambiente (BRASIL, 2012).

Sendo a educação um direito social, público e subjetivo previsto na Constituição federal, é também a Educação ambiental um direito de todos e para todos os alunos. Quem são esses alunos? O aluno padrão, idealizado na mente do professor?

Como trabalhar a Educação ambiental com o aluno que sobrevive da catação do lixo, o domiciliado na zona rural cuja residência não tem saneamento básico, o inserido em situação de vulnerabilidade social, e em tantas outras realidades existentes no Brasil, cuja presença na sala de aula advém de compromissos oriundos de programas governamentais como o Bolsa Família?

Enfim, muitos são os questionamentos. A partir de uma revisão de literatura, este ensaio apresenta uma reflexão sobre os aspectos que devem ser considerados 
pelo professor da Educação básica no planejamento e desenvolvimento de práticas de ensino acerca das questões ambientais para garantir o atendimento às necessidades cognitivas dos alunos, tendo em vista a diversidade socioeconômica e cultural destes.

\section{A CRISE DA EDUCAÇÃO AMBIENTAL}

Na introdução do livro Educação e Meio Ambiente: Uma Relação Intrínseca, Luzzi (2012) afirma que a chamada Educação ambiental tem se desenvolvido em direções diferentes, uma vez que apesar das reflexões teóricas de um grupo de intelectuais definirem-na e caracterizarem-na com um enfoque socioambiental na formação de cidadãos críticos, na prática, a Educação ambiental escolar encontra-se bem distante da realidade teórica.

O quadro 1 abaixo apresenta uma síntese da discussão provocada pelo autor.

Quadro 1 - Síntese da evolução da Educação ambiental nas reflexões teóricas e na prática. Fonte: Luzzi (2012). Nota: Texto adaptado pela autora.

\begin{tabular}{|l|l|}
\hline \multicolumn{1}{|c|}{ Reflexões teóricas } & \multicolumn{1}{|c|}{ Prática } \\
\hline $\begin{array}{l}\text { Aborda a formação de um sujeito com capacidade de } \\
\text { interpretar o mundo para atuar nele. }\end{array}$ & $\begin{array}{l}\text { Não evolui além dos conhecimentos descritivos e } \\
\text { explicativos. }\end{array}$ \\
\hline $\begin{array}{l}\text { Aborda a complexidade da realidade por meio da } \\
\text { interdisciplinaridade dos conhecimentos. }\end{array}$ & $\begin{array}{l}\text { Os eixos transversais fragmentam ainda mais a unidade } \\
\text { da realidade e não passam de uma atividade isolada } \\
\text { gerada a partir da boa vontade de um ou mais } \\
\text { professores. }\end{array}$ \\
\hline $\begin{array}{l}\text { Construção de uma aproximação entre as relações entre } \\
\text { sociedade e ambiente, e seus múltiplos conflitos } \\
\text { relacionados à cultura e aos valores envolvidos na } \\
\text { cotidianidade. }\end{array}$ & $\begin{array}{l}\text { Perpetuam-se as oficinas de papel reciclado, aulas sobre } \\
\text { aquecimento global, estímulo à separação e reciclagem } \\
\text { do lixo, organização de hortas orgânicas, trilhas de } \\
\text { interpretação ambiental, entre outros. }\end{array}$ \\
\hline
\end{tabular}

À vista disso, Luzzi (2012) ressalta a crise da Educação ambiental cuja prática se reduz, na maioria das vezes, a atividades ecológicas e a eixos transversais, ignorando o conhecimento integrado da realidade pelo ser humano e suas problemáticas de vida.

Ao revisitarmos os propósitos da dimensão ambiental da educação, entendemos que ela visa despertar nos alunos valores de cooperação e de respeito ao meio ambiente em todos os seus aspectos: físicos, químicos, biológicos e sociais. Isso exige 
do professor o desenvolvimento de atividades de ensino que abranjam conteúdos atitudinais.

Zabala (1998) alerta sobre a complexidade desse trabalho em vista da atuação determinante das próprias características e do componente afetivo na aprendizagem desses conteúdos:

[...] O caráter conceitual dos valores, as normas e as atitudes, [...] o sentido que pode ter o valor solidariedade, ou o respeito às minorias, não se aprende apenas com o conhecimento do que cada uma destas idéias [sic] representa. As atividades de ensino necessárias têm que abarcar, junto com os campos cognitivos, os afetivos e condutuais, dado que os pensamentos, os sentimentos e o comportamento de uma pessoa não depende só do socialmente estabelecido, como, sobretudo, das relações pessoais que cada um estabelece com o objeto da atitude ou do valor [...]. (ZABALA, 1998, p. 83).

Em suma, Zabala (1998) indica medidas a serem consideradas nas sequências de aprendizagem para conteúdos atitudinais, a saber: a) adaptar o caráter dos conteúdos às necessidades e situações reais dos alunos, aproveitando os conflitos que nelas se apresentam para conduzir o trabalho do professor; b) refletir criticamente sobre as normas sociais de convivência para que estas integrem as próprias normas; c) favorecer modelos de atitudes que se queiram desenvolver, promovendo um processo de mudança atitudinal dos professores e alunos; d) estimular a autonomia moral de cada aluno.

\section{REFLETINDO SOBRE A DIVERSIDADE, AS SUBJETIVIDADES E OS SABERES DOS EDUCANDOS NA PRÁTICA PEDAGÓGICA}

No prólogo da obra Para Além da Aprendizagem: Educação Democrática para um Futuro Humano, Biesta (2013) faz uma crítica aos fundamentos humanistas da educação moderna, posto que especificam o que a criança, o estudante, os "recémchegados" devem tornar-se antes mesmo de lhes dar a oportunidade de mostrarem quem são e quem querem ser. Dessa forma, as singularidades de cada um não são consideradas. 
Para o autor, a educação é sempre uma intervenção na vida de alguém motivada pela ideia de tornar essa vida melhor e talvez até mais humana, porém práticas educacionais tidas como práticas de socialização cuja preocupação seja a inserção de recém-chegados numa ordem sociopolítica e cultural estabelecida contribuem para a reprodução de desigualdades existentes. Portanto, Biesta (2013, p. 26) propõe uma abordagem contrária à maneira tradicional de pensar a educação que é "[...] focar as maneiras pelas quais o novo início de cada indivíduo pode tornar-se presença [...]", visto que "[...] só podemos nos tornar presença num mundo povoado por outros que não são como nós [...]".

Dessa forma, a educação não pode ser do ponto de vista de um educador tentando produzir autônomos racionais ou liberar o potencial racional dos alunos, e sim de um educador responsável pela vinda ao mundo - compreendido como um mundo de pluralidade e diferença - de seres que se tornam presença (BIESTA, 2013).

A escola, como espaço de socialização do conhecimento científico, instituiu-se com o objetivo de universalizar a educação para todos. A concepção acrítica desse objetivo conduz à realização de práticas educativas homogeneizadas no interior escolar.

Meirieu (2005) alerta sobre o perigo do desejo de homogeneidade na escola, visto que pode significar sua ruína. Isso porque faz da escola, quando ideológica, um lugar de enclausuramento que submete o aluno à ideologia dominante; quando sociológica, um gueto em que o aluno reside obrigatoriamente vendo sua perspectiva limitada pela fatalidade da reprodução social; quando psicológica, um casulo aconchegante que protege o aluno de qualquer descoberta que possa abrir-lhe outros horizontes; e, quando intelectual, um lugar pobre de interações possíveis, sem a possibilidade de colocar o conhecimento à avaliação de outros alunos com pensamentos e percepções diferentes. 
No que diz respeito à heterogeneidade de níveis de conhecimento apresentados pelos alunos, Meirieu (2005) defende que ela nunca foi de fato um problema para os professores, já que pode ser ignorada ou resolvida da melhor maneira. Todavia, o autor afirma ser a heterogeneidade de comportamentos, caracterizada pela não adesão total dos alunos às normas institucionais, que abalam a estrutura escolar.

Ainda segundo Meirieu (2005), o professor, ao organizar uma aula para trabalhar os conteúdos programáticos nas melhores condições, deseja que os alunos queiram aprender o que é previsto para aquele dia, decepcionando-se quando eles não estão dispostos a receberem livremente o que lhes é imposto. Desapontado, esse professor acaba por desconsiderar a história pessoal dos alunos, suas inquietações familiares e preocupações específicas, bem como os diferentes centros de interesse de cada um.

Os apontamentos feitos por Meirieu (2005) evidenciam a necessidade de o professor compreender como se dá o processo de aprendizagem dos conteúdos pelo aluno.

Ao discutir a concepção da aprendizagem, Zabala (1998) aponta a desconfiança de muitos educadores em relação às contribuições da psicologia da aprendizagem ante a existência de referenciais teóricos com distintas interpretações dos processos de ensino-aprendizagem e a falta de consenso científico entre eles.

Essas diferentes correntes compartilham uma série de princípios que, de acordo com Zabala (1998), são constatados na prática pelos educadores e constituídos como senso comum:

[...] as aprendizagens dependem das características singulares de cada um dos aprendizes; correspondem, em grande parte, às experiências que cada um viveu desde o nascimento; a forma como se aprende e o ritmo da aprendizagem variam segundo as capacidades, motivações e interesses de cada um dos meninos e meninas; enfim, a maneira e a forma como se produzem as aprendizagens são resultado de processos que sempre são singulares e pessoais [...] (ZABALA, 1998, p. 34). 
Embora reconheça a dificuldade de se nortear o trabalho pedagógico pela atenção à diversidade, tida como ação de atender e considerar as diferenças que possam surgir na sala de aula, Zabala (1998) não isenta o professor de seu compromisso assumido com a formação dos alunos:

Sem dúvida, é difícil conhecer os diferentes graus de conhecimento de cada menino e menina, identificar o desafio de que necessitam, saber que ajuda requerem e estabelecer a avaliação apropriada para cada um deles a fim de que se sintam estimulados a se esforçar em seu trabalho. Mas o fato de que custe não deve nos impedir de buscar meios ou formas de intervenção que, cada vez mais, nos permitam dar uma resposta adequada às necessidades pessoais de todos e cada um de nossos alunos (ZABALA, 1998, p. 36, grifo nosso).

O conhecimento sobre como se dá a produção das aprendizagens pode contribuir com o trabalho do professor, quer aproveitando-se das potencialidades que as sequências didáticas podem oferecer à significância das aprendizagens, quer despertando a atenção à diversidade (ZABALA, 1998).

Numa concepção construtivista, Zabala (1998, p. 63), afirma que:

[...] a aprendizagem é uma construção pessoal que cada menino e cada menina realizam graças à ajuda que recebem de outras pessoas. Esta construção, através da qual podem atribuir significado a um determinado objeto de ensino, implica a contribuição por parte da pessoa que aprende, de seu interesse e disponibilidade, de seus conhecimentos prévios e de sua experiência [...].

Ora, somente um professor comprometido com a formação de cidadãos críticos em relação à realidade socioambiental em que vivem é capaz de repudiar a mera transmissão de informações e conceitos e optar pelo trabalho com conteúdos atitudinais, visando à formação de valores sociais e éticos. Somente esse professor pode perceber a riqueza e as contribuições dos saberes e experiências dos alunos para a prática pedagógica dele.

Sobre a mera transmissão de informações e conceitos, Freire (1987) faz críticas à concepção de educação na qual o papel do educador é transferir conteúdos sem qualquer relação com a realidade social dos alunos. 
Essa educação, que Freire (1979) denomina bancária, considera o professor como aquele que ensina a ignorantes e o educando como aquele que recebe passivamente os conhecimentos, como um depósito vazio que vai se enchendo.

Dessa forma, o educando, que é o próprio homem, ao arquivar tudo o que recebe acaba por desumanizar-se, pois perde seu poder de criar e transformar o mundo, deixando de ser o sujeito de sua ação. Por não estimular a criação, a educação bancária forma indivíduos medíocres (alunos) e transforma o professor em um acomodado, uma vez que não é desafiado pelos seus alunos (FREIRE, 1979).

A teoria freiriana preconiza o respeito aos saberes dos alunos socialmente construídos na prática comunitária e o estímulo do senso crítico do educando por meio da dialogicidade entre educador e educando tornando possível a relação desses saberes com o ensino dos conteúdos:

[...] Por que não aproveitar a experiência que têm os alunos de viver em áreas da cidade descuidadas pelo poder público para discutir, por exemplo, a poluição dos riachos e dos córregos e os baixos níveis de bem-estar das populações, os lixões e os riscos que oferecem à saúde das gentes. Por que não há lixões no coração dos bairros ricos e mesmo puramente remediados dos centros urbanos? [...] (FREIRE, 1996, p. 30).

Aproximando a teoria freiriana à teoria histórico-cultural da Escola de Vygotsky em razão de se basearem epistemologicamente no materialismo histórico-dialético, percebemos a importância dada por ambas à influência do contexto social e histórico no desenvolvimento do sujeito.

É na dialogicidade, na abertura ao outro que o indivíduo aprende e apreende o mundo em que vive. A relação dele com o mundo é mediada por instrumentos historicamente construídos pela humanidade e por signos.

Na teoria vygotskyana, a aprendizagem e o desenvolvimento são processos complexamente inter-relacionados desde os primeiros dias de vida da criança e têm início muito antes de ela frequentar a escola (VYGOTSKY, 2009). 
Vygotsky traz o conceito de zona de desenvolvimento proximal (ZDP) que

permite o entendimento de como se dá o "estado de desenvolvimento" da criança:

[...] é a distância entre o nível de desenvolvimento real, que se costuma determinar através da solução independente de problemas, e o nível de desenvolvimento potencial, determinado através da solução de problemas sob a orientação de um adulto ou em colaboração com companheiros mais capazes (VYGOTSKY, 2007, p. 97).

Sendo as funções psíquicas superiores (a saber: atenção, memória, imaginação, pensamento e linguagem) processos mediados pelo emprego de signos, a criança aprende por meio da imitação e da colaboração com o adulto, sempre podendo fazer mais do que sozinha. Esse fazer é determinado pelo estado de desenvolvimento dela e de suas potencialidades intelectuais (VYGOTSKY, 2009, p. 329).

Numa visão prospectiva, esse conceito de ZDP serve de instrumento para o planejamento de atividades de ensino pela equipe pedagógica que não favoreçam apenas o acesso ao que a criança já sabe, isto é, ao que já foi atingido por meio do desenvolvimento, mas também àquilo que está começando a se consolidar (VYGOTSKY, 2007).

Ott (2009) critica a escola brasileira por desconsiderar as necessidades dos educandos e exigir uma adaptação passiva para todos, destacando os que mais se ajustam e concorrem para a manutenção dos ideais já estabelecidos. Logo, defende que a escola deve trabalhar com os problemas reais do contexto em que a comunidade está inserida e propõe o ensino por meio de solução de problemas.

Para implementação dessa proposta de ensino,

[...] Precisa-se, em primeiro lugar, aprender a ver a realidade, e talvez seja esta a tarefa fundamental da escola e, vendo-a, descobrir aqueles problemas que incomodam a população e que, gradativamente, pelo conhecimento e sentimento, deverão também incomodar o aluno (OTT, 2009, p. 68).

Dessa forma, professor e aluno se transformam em pesquisadores e conhecedores da realidade para compreenderem o problema e preverem alternativas corretas ou adequadas de solução e a avaliação da aprendizagem se dá naturalmente 
no contato do aluno com a experiência e na análise realizada junto com o professor (OTT, 2009).

Confluindo com a proposta de Ott (2009), Lopes (2004) já discutia a desvinculação entre os objetivos educacionais propostos nos currículos dos cursos e a realidade social, visto que os conteúdos não apresentam ligação com as experiências de vida dos alunos.

Como crítica à metodologia de ensino utilizada pelo professor, caracterizada pelo desenvolvimento de atividades expositivas que não estimulam o pensamento criativo dos alunos e com pouco ou nenhum espaço para discussão dos conteúdos, a autora aponta para a necessidade de se repensar o processo de planejamento do ensino (LOPES, 2004).

Esse processo deverá pautar-se pela ação pedagógica direcionada e integrar-se dialeticamente (de diferentes pontos de vista) ao concreto (realidade histórico-social) do educando, buscando transformá-lo (produção de novos conhecimentos) (LOPES, 2004).

Nesse sentido, o ponto de referência para o planejamento das atividades educativas seriam as problemáticas sociocultural, econômica e política do contexto em que a escola está inserida e se efetivaria de forma participativa e coletivamente por professores, alunos, pessoal técnico-pedagógico e administrativo, bem como os pais com vistas à solução de problemas comuns (LOPES, 2004).

Isto posto, o estudo da escola em suas relações com a comunidade em que está inserida e da clientela escolar baseará a definição dos objetivos de ensino, a sistematização dos conteúdos a serem estudados, a seleção dos procedimentos didáticos e a avaliação da aprendizagem por meio do projeto político-pedagógico.

Concluindo, Lopes (2004) ressalta que o trabalho didático em um processo educativo que se propõe transformador, deverá fundamentar-se na: a) definição de 
objetivos voltados para a reelaboração e produção de conhecimento; b) análise crítica dos conteúdos do currículo escolar visando à identificação dos conhecimentos essenciais à compreensão da realidade histórico-social do educando; c) articulação de uma metodologia de ensino pelo professor caracterizada por uma variedade de atividades e de recursos auxiliares estimuladores da reflexão, investigação e curiosidade do educando e; d) avaliação da aprendizagem que se preocupa com a qualidade da reelaboração e da produção de novos conhecimentos demonstrada pelos alunos com base na matéria estudada.

Numa concepção de heterogeneidade do processo de aprendizagem dos alunos, Almeida (2012) partilha sua colaboração no processo de formação docente vivenciado com uma professora de uma escola do sistema municipal de Vitória-ES e relata a construção de um projeto em multiníveis como "estratégia educacional possível, na concretização da prática pedagógica numa perspectiva inclusiva do currículo escolar" (ALMEIDA, 2012, p. 77).

Considerando que não há um modelo único de projeto ou aula em multiníveis, mas, sim discussões e direcionamentos que servem como passo inicial a ser dado por todos na escola na busca por um ensino que atenda a todos os alunos, Almeida (2012) elenca: a) uma aula em multiníveis deve atentar para o contexto geral da turma como forma de garantir um currículo comum a todos os alunos; b) as atividades em multiníveis podem ser realizadas de formas distintas em conformidade com os objetivos do professor; c) a investigação didática e acompanhamento sistemático dos níveis de aprendizagem dos alunos.

Durante a realização do projeto, Almeida (2012, p. 85) observou que:

[...] o trabalho em multiníveis permite um processo de aprendizagem em que todos têm possibilidade de exprimir opiniões e conhecimentos, quando são desafiados a partir de suas potencialidades e, ainda, podem obter sucesso na tarefa, aumentando sua autoestima perante os colegas. 
Sacristán (2002, p. 15) esclarece que a diversidade e a desigualdade são manifestações intrínsecas dos seres humanos, dos fatos sociais e das culturas, sendo “[...] tão normal quanto a própria vida, e devemos acostumar-nos a viver com ela e a trabalhar a partir dela [...]".

O autor aponta como estratégias para se trabalhar com a complexidade do equilíbrio entre a diversidade e a igualdade no ensino: currículo adaptado, metodologia diversificada, potencializar o que cada aluno tem de melhor, observar as necessidades de cada estudante, diversificação dos recursos didáticos e a revisão da organização escolar (SACRISTÁN, 2002).

Eis então o papel do professor nesse processo de construção pessoal da aprendizagem: propor atividades que mesclem os conhecimentos prévios e os conhecimentos a serem sabidos, que desafiem o aluno a ponto de se sentir capaz e com vontade de resolvê-la, que intervenha adequadamente nos progressos e nas dificuldades manifestadas pelos alunos exortando a autonomia deles.

\section{CONSIDERAÇÕES FINAIS}

Pretendeu-se com este ensaio teórico elaborar uma reflexão sobre os aspectos que devem ser considerados pelo professor da Educação básica no planejamento e desenvolvimento de suas práticas de ensino acerca das questões ambientais para garantir o atendimento às necessidades cognitivas dos alunos, tendo em vista a diversidade socioeconômica e cultural deles.

No decorrer do estudo, destacam-se pontos comuns nas ideias apresentadas pelos autores mencionados: a) a aprendizagem dos alunos se dá em função de suas características singulares: experiência de vida, contexto sociocultural e necessidades próprias de cada um; b) os saberes socialmente construídos dos alunos podem contribuir para com a prática educativa do professor, e; c) a crítica à transmissão 
mecânica de conteúdos sem qualquer estabelecimento de relação com o contexto social do aluno.

Falar de uma educação para todos soa quase utópico, visto que, na realidade, o currículo verticalmente instituído e as condições de trabalho do professor concorrem para uma prática educativa padrão que não considera a pluralidade e as diferenças.

Obviamente, não podemos desconsiderar as dificuldades de se nortear o trabalho pedagógico pela atenção à diversidade. A desvalorização da profissão docente, na forma de uma má remuneração, a pressão por excelentes resultados em avaliações de grande escala, carga horária extensa, alta rotatividade de professores em designação temporária são algumas condições que atrapalham o desenvolvimento de uma prática educativa verdadeiramente inclusiva, fazendo com que o professor planeje e ministre aulas únicas como se todos os alunos fossem idênticos em seus anseios, ritmos, culturas e condições socioeconômicas.

É preciso frisar que a atenção à diversidade não se restringe somente à figura do professor. Embora seja este um importante protagonista de uma educação inclusiva, a gestão escolar e o poder público têm grande responsabilidade na garantia desse direito subjetivo que é a educação, pois a universalização da educação não exime a escola de exercer sua autonomia por meio de seu Projeto Político-Pedagógico (PPP). É na constituição e reelaboração do PPP que a comunidade escolar pode decidir ações, metas e objetivos que contemplem as especificidades de sua clientela por meio de um trabalho pedagógico personalizado possibilitado pela legislação educacional tendo em vista as condições sociais e geográficas em que está inserida.

\section{REFERÊNCIAS}

ALMEIDA, M. L. D. A prática pedagógica inclusiva: o ensino em multiníveis como possibilidade. In: ALMEIDA, M. L. D.; RAMOS, I. D. O. Diálogos sobre práticas pedagógicas inclusivas. 1. ed. Curitiba: Appris, 2012. 
BIESTA, G. Para além da aprendizagem: educação democrática para um futuro humano. Belo Horizonte: Autêntica Editora, 2013.

BRASIL. Resolução № 2, de 15 de junho de 2012. Estabelece as Diretrizes Curriculares Nacionais para a Educação Ambiental. Disponível em: <http://portal.mec.gov.br/index.php?option=com_docman\&view=download\&alias=1 0988-rcp002-12-pdf\&category_slug=maio-2012-pdf\&Itemid=30192>. Acesso em: 12 nov. 2016.

FREIRE, P. Educação e mudança. Tradução de Moacir Gadotti e Lillian Lopes Martin. Rio de Janeiro: Paz e Terra, 1979.

. Pedagogia do oprimido. 17ạ. ed. Rio de Janeiro: Paz e Terra, 1987. . Pedagogia da autonomia: saberes necessários à prática educativa.

São Paulo: Paz e Terra, 1996.

LOPES, A. O. Planejamento do ensino numa perspectiva crítica de educação. In: VEIGA, I. P. A. Repensando a didática. 25. ed. Campinas: Papirus, 2004.

LUZZI, D. Educação e meio ambiente: uma relação intrínseca. Barueri: Manole, 2012. MEIRIEU, P. O cotidiano da escola e da sala de aula: o fazer e o compreender. Tradução de Fátima Murad. Porto Alegre: Artmed, 2005.

OTT, M. B. Ensino por meio de solução de problemas. In: CANDAU, V. M. A didática em questão. 29ạ. ed. Petrópolis: Editora Vozes, 2009.

PEREIRA, C. A. R.; MELO, J. V. D.; FERNANDES, A. L. T. A educação ambiental como estratégia da Atenção Primária à Saúde. Revista Brasileira de Medicina de Família e Comunidade, Florianópolis, v. 7, p. 108-116, maio 2012.

SACRISTÁN, J. G. A construção do discurso sobre a diversidade e suas práticas. In: ALCUDIA, R., et al. Atenção à diversidade. Tradução de Daisy Vaz de Moraes. Porto Alegre: Artmed, 2002. 
VYGOTSKY, L. S. A formação social da mente: o desenvolvimento dos processos psicológicos superiores. Tradução de José Cipolla Neto; Luís Silveira Menna Barreto e Solange Castro Afeche. 7ạ. ed. São Paulo: Martins Fontes, 2007.

. A construção do pensamento e da linguagem. Tradução de Paulo Bezerra. 2a . ed. São Paulo: Editora WMF Martins Fontes, 2009.

ZABALA, A. A prática educativa: como ensinar. Tradução de Ernani F. da Fonseca Rosa. Porto Alegre: Artmed, 1998. 